\title{
An Extragradient Method and Proximal Point Algorithm for Inverse Strongly Monotone Operators and Maximal Monotone Operators in Banach Spaces
}

\author{
Somyot Plubtieng and Wanna Sriprad \\ Department of Mathematics, Faculty of Science, Naresuan University, Phitsanulok 65000, Thailand
}

Correspondence should be addressed to Somyot Plubtieng, somyotp@nu.ac.th

Received 6 January 2009; Accepted 22 April 2009

Recommended by Nanjing Jing Huang

\begin{abstract}
We introduce an iterative scheme for finding a common element of the solution set of a maximal monotone operator and the solution set of the variational inequality problem for an inverse strongly-monotone operator in a uniformly smooth and uniformly convex Banach space, and then we prove weak and strong convergence theorems by using the notion of generalized projection. The result presented in this paper extend and improve the corresponding results of Kamimura et al. (2004), and Iiduka and Takahashi (2008). Finally, we apply our convergence theorem to the convex minimization problem, the problem of finding a zero point of a maximal monotone operator and the complementary problem.
\end{abstract}

Copyright (c) 2009 S. Plubtieng and W. Sriprad. This is an open access article distributed under the Creative Commons Attribution License, which permits unrestricted use, distribution, and reproduction in any medium, provided the original work is properly cited.

\section{Introduction}

Let $E$ be a Banach space with norm $\|\cdot\|$, let $E^{*}$ denote the dual of $E$ and let $\langle x, f\rangle$ denote the value of $f \in E^{*}$ at $x \in E$. Let $T: E \rightarrow E^{*}$ be an operator. The problem of finding $v \in E$ satisfying $0 \in T v$ is connected with the convex minimization problems and variational inequalities. When $T$ is maximal monotone, a well-known method for solving the equation $0 \in T v$ in Hilbert space $H$ is the proximal point algorithm (see [1]): $x_{1}=x \in H$ and

$$
x_{n+1}=J_{r_{n}} x_{n}, \quad n=1,2, \ldots,
$$

where $r_{n} \subset(0, \infty)$ and $J_{r}=(I+r T)^{-1}$ for all $r>0$ is the resolvent operator for $T$. Rockafellar (see [1]) proved the weak convergence of the algorithm (1.1). These results were extended to 
more general Banach spaces; see Kamimura and Takahashi [2] and Ohsawa and Takahashi [3]. In 2004, Kamimura et al. [4] considered the algorithm (1.2) in a uniformly smooth and uniformly convex Banach space $E$, namely,

$$
x_{n+1}=J^{-1}\left(\alpha_{n} J\left(x_{n}\right)+\left(1-\alpha_{n}\right) J\left(J_{r_{n}} x_{n}\right)\right), \quad n=1,2, \ldots,
$$

where $J_{r}=(J+r T)^{-1} J, J$ is the duality mapping of $E$. They showed that the algorithm (1.2) converges weakly to some element of $T^{-1} 0$ provided that the sequences $\left\{\alpha_{n}\right\}$ and $\left\{r_{n}\right\}$ of real numbers are chosen appropriately.

Let $C$ be a nonempty closed convex subset of $E$ and let $A$ be a monotone operator of $C$ into $E^{*}$. The variational inequality problem is to find a point $u \in C$ such that

$$
\langle v-u, A u\rangle \geq 0, \quad \forall v \in C
$$

The set of solutions of the variational inequality problem is denoted by $V I(C, A)$. Such a problem is connected with the convex minimization problem, the complementarity problem, the problem of finding a point $u \in E$ satisfying $0=A u$ and so on. An operator $A$ of $C$ into $E^{*}$ is said to be inverse-strongly-monotone, if there exists a positive real number $\alpha$ such that

$$
\langle x-y, A x-A y\rangle \geq \alpha\|A x-A y\|^{2}
$$

for all $x, y \in C$. In such a case, $A$ is said to be $\alpha$-inverse-strongly-monotone. If an operator $A$ of $C$ into $E^{*}$ is $\alpha$-inverse-strongly-monotone, then $A$ is Lipschitz continuous, that is, $\|A x-A y\| \leq$ $(1 / \alpha)\|x-y\|$ for all $x, y \in C$.

In a Hilbert space $H$, one method of solving a point in $\operatorname{VI}(C, A)$ is the projection algorithm which starts with any $x_{1}=x \in C$ and updates iteratively $x_{n+1}$ according to the formula

$$
x_{n+1}=P_{C}\left(x_{n}-\lambda_{n} A x_{n}\right)
$$

for every $n=1,2, \ldots$, where $A$ is a monotone operator of $C$ in to $H, P_{C}$, is the metric projection of $H$ onto $C$ and $\left\{\lambda_{n}\right\}$ is a sequence of positive numbers. In the case where $A$ is inverse-strongly-monotone, Iiduka et al. [5] proved that the sequence $\left\{x_{n}\right\}$ generated by (1.5) converges weakly to some element of $\operatorname{VI}(C, A)$.

Recently, Iiduka and Takahashi [6] introduced the following iterative scheme for finding a solution of the variational inequality problem for an inverse-strongly-monotone operator $A$ in Banach space: $x_{1}=x \in C$ and

$$
x_{n+1}=\Pi_{C} J^{-1}\left(J x_{n}-\lambda_{n} A x_{n}\right)
$$

for every $n=1,2, \ldots$, where $\Pi_{C}$ is the generalized metric projection from $E$ onto $C, J$ is the duality mapping from $E$ into $E^{*}$, and $\left\{\lambda_{n}\right\}$ is a sequence of positive numbers. They proved that the sequence $\left\{x_{n}\right\}$ generated by (1.6) converges weakly to some element of $\operatorname{VI}(C, A)$. 
In this paper, motivated by the idea of extragradient method [7], Kamimura et al. [4], and Iiduka and Takahashi [6], we introduce the iterative scheme (3.1) for finding a common element of the set of zero of a maximal monotone operator and the solution set of the variational inequality problem for an inverse-strongly-monotone operator in a 2-uniformly convex and uniformly smooth Banach space. Then, the weak and strong convergence theorems are proved under some parameters controlling conditions. Further, we apply our convergence theorem to the convex minimization problem, the problem of finding a zero point of a maximal monotone operator and the complementary problem. The results obtained in this paper improve and extend the corresponding results of Kamimura et al. [4], and Iiduka and Takahashi [6], and many others.

\section{Preliminaries}

Let $E$ be a real Banach space. When $\left\{x_{n}\right\}$ is a sequence in $E$, we denote strong convergence of $\left\{x_{n}\right\}$ to $x \in E$ by $x_{n} \rightarrow x$ and weak convergence by $x_{n} \rightarrow x$. An operator $T \subset E \times E^{*}$ is said to be monotone if $\left\langle x-y, x^{*}-y^{*}\right\rangle \geq 0$ whenever $\left(x, x^{*}\right),\left(y, y^{*}\right) \in T$. We denote the set $\{x \in E: 0 \in T x\}$ by $T^{-1} 0$. A monotone $T$ is said to be maximal if its graph $G(T)=\{(x, y): y \in T x\}$ is not properly contained in the graph of any other monotone operator. If $T$ is maximal monotone, then the solution set $T^{-1} 0$ is closed and convex.

The normalized duality mapping $J$ from $E$ into $E^{*}$ is defined by

$$
J(x)=\left\{x^{*} \in E^{*}:\left\langle x, x^{*}\right\rangle=\|x\|^{2}=\left\|x^{*}\right\|^{2}\right\} .
$$

We recall (see [8]) that $E$ is reflexive if and only if $J$ is surjective; $E$ is smooth if and only if $J$ is single-valued; $E$ is strictly convex if and only if $J$ is one-to-one; if $E$ is uniformly smooth, then $J$ is uniformly norm-to-norm continuous on each bounded subset of $E$. We note that in a Hilbert space, $H, J$ is the identity operator. The definitions of the strict (uniform) convexity, (uniformly) smoothness of Banach spaces and related properties can be found in [8].

The duality $J$ from a smooth Banach space $E$ into $E^{*}$ is said to be weakly sequentially continuous [9] if $x_{n} \rightarrow x$ implies $J x_{n} \rightarrow^{*} J x$, where $\rightarrow^{*}$ implies the weak ${ }^{*}$ convergence. defined by

Let $E$ be a Banach space. The modulus of convexity of $E$ is the function $\delta:[0,2] \rightarrow[0,1]$

$$
\delta(\varepsilon)=\inf \left\{1-\left\|\frac{x+y}{2}\right\|: x, y \in E,\|x\|=\|y\|=1,\|x-y\| \geq \varepsilon\right\}
$$

$E$ is uniformly convex if and only if $\delta(\varepsilon)>0$ for all $\varepsilon \in(0,2]$. Let $p$ be a fixed real number with $p \geq 2$. Then $E$ is said to be $p$-uniformly convex if there exists a constant $c>0$ such that $\delta(\varepsilon) \geq c \varepsilon^{p}$ for all $\varepsilon \in[0,2]$. For example, see $[10,11]$ for more detials. Observe that every $p$-uniformly convex space is uniformly convex. One should note that no Banach space is $p$ uniformly convex for $1<p<2$; see [11] for more details. It is well known that Hilbert and Lebesgue $L^{q}(1<q \leq 2)$ spaces are 2-uniformly convex and uniformly smooth. 
Lemma 2.1 (see $[12,13]$ ). Let E be a 2-uniformly convex Banach space. Then, for all $x, y \in E$, one has

$$
\|x-y\| \leq \frac{2}{c^{2}}\|J x-J y\|
$$

where $J$ is the normalized duality mapping of $E$ and $0<c \leq 1$.

The best constant $1 / c$ in Lemma 2.1 is called the 2-uniformly convex constant of $E$; see [10].

Lemma 2.2 (see [13]). Let E be a uniformly convex Banach space. Then for each $r>0$, there exists a strictly increasing, continuous, and convex function $K:[0, \infty) \rightarrow[0, \infty)$ such that $K(0)=0$ and

$$
\|\lambda x+(1-\lambda y)\|^{2} \leq \lambda\|x\|^{2}+(1-\lambda)\|y\|^{2}-\lambda(1-\lambda) K(\|x-y\|)
$$

for all $x, y \in\{z \in E:\|z\| \leq r\}$ and $\lambda \in[0,1]$.

Let $E$ be a smooth Banach space. The function $\phi: E \times E \rightarrow \mathbb{R}$ defined by

$$
\phi(x, y)=\|x\|^{2}-2\langle x, J y\rangle+\|y\|^{2} \quad \forall x, y \in E
$$

is studied by Alber [14], Kamimura and Takahashi [2], and Reich [15]. It is obvious from the definition of $\phi$ that $(\|x\|-\|y\|)^{2} \leq \phi(x, y) \leq(\|x\|+\|y\|)^{2}$ for all $x, y \in E$.

Let $E$ be a reflexive, strictly convex smooth Banach space, and $C$ a nonempty closed convex subset of $E$. By Alber [14], for each $x \in E$, there corresponds a unique element $x_{0} \in C$ (denoted by $\Pi_{C}(x)$ ) such that

$$
\phi\left(x_{0}, x\right)=\min _{y \in C} \phi(y, x)
$$

The mapping $\Pi_{C}(x)$ is called the generalized projection from $E$ onto $C$. If $E$ is a Hilbert space, then $\Pi_{C}(x)$ is coincident with the metric projection from $E$ onto $C$.

Lemma 2.3 (see [2]). Let E be a uniformly convex smooth Banach space, and let $\left\{x_{n}\right\}$ and $\left\{y_{n}\right\}$ be sequences in $E$. If $\left\{x_{n}\right\}$ or $\left\{y_{n}\right\}$ is bounded and $\lim _{n \rightarrow \infty} \phi\left(x_{n}, y_{n}\right)=0$, then $\lim _{n \rightarrow \infty}\left\|x_{n}-y_{n}\right\|=0$.

Lemma 2.4 (see $[2,14])$. Let $E$ be a smooth Banach space and $C$ be a nonempty, closed convex subset of $E$. Let $x \in E$ and let $x_{0} \in C$. Then $\phi\left(x_{0}, x\right)=\min _{y \in C} \phi(y, x)$ if and only if $\left\langle y-x_{0}, J x-J x_{0}\right\rangle \leq 0$ for all $y \in C$.

Lemma 2.5 (see $[2,14]$ ). Let $E$ be a reflexive, strictly convex, and smooth Banach space, $C$ a nonempty, closed convex subset of $E$, and $x \in E$. Then

$$
\phi\left(y, \Pi_{C}(x)\right)+\phi\left(\Pi_{C}(x), x\right) \leq \phi(y, x) \quad \forall y \in C .
$$

Let $E$ be a reflexive, strictly convex, and smooth Banach space and $J$ the duality mapping from $E$ into $E^{*}$. Then $J^{-1}$ is also single-valued, one-to-one, surjective, and it is the 
duality mapping from $E^{*}$ into $E$. We make use of the following mapping $V$ studied in Alber [14]:

$$
V\left(x, x^{*}\right)=\|x\|^{2}-2\left\langle x, x^{*}\right\rangle+\left\|x^{*}\right\|^{2}
$$

for all $x \in E$ and $x^{*} \in E^{*}$. In other words, $V\left(x, x^{*}\right)=\phi\left(x, J^{-1}\left(x^{*}\right)\right)$ for all $x \in E$ and $x^{*} \in E^{*}$.

Lemma 2.6 (see [14]). Let $E$ be a reflexive, strictly convex, and smooth Banach space and let $V$ be as in (2.8). Then

$$
V\left(x, x^{*}\right)+2\left\langle J^{-1}\left(x^{*}\right)-x, y^{*}\right\rangle \leq V\left(x, x^{*}+y^{*}\right)
$$

for all $x \in E$ and $x^{*}, y^{*} \in E^{*}$.

Let $E$ be a smooth, strictly convex, and reflexive Banach space and let $T \subset E \times E^{*}$ be a maximal monotone operator. Then for each $r>0$ and $x \in E$, there corresponds a unique element $x_{r} \in D(T)$ satisfying

$$
J(x) \in J\left(x_{r}\right)+r T\left(x_{r}\right)
$$

see Barbu [16] or Takahashi [17]. We define the resolvent of $T$ by $J_{r} x=x_{r}$. In other words, $J_{r}=(J+r T)^{-1} J$ for all $r>0$. It easy to show that $T^{-1} 0=F\left(J_{r}\right)$ for all $r>0$, where $F\left(J_{r}\right)$ denotes the set of all fixed points of $J_{r}$. We can also define, for each $r>0$, the Yosida approximation of $T$ by $A_{r}=r^{-1}\left(J-J J_{r}\right)$. We know that $\left(J_{r} x, A_{r} x\right) \in T$ for all $r>0$ and $x \in E$. We also know the following.

Lemma 2.7 (see [18]). Let $E$ be a smooth, strictly convex, and reflexive Banach space, let $T \subset E \times E^{*}$ be a maximal monotone operator with $T^{-1} 0 \neq \emptyset$, let $r>0$ and let $J_{r}=(J+r T)^{-1} \mathrm{~J}$. Then

$$
\phi\left(x, J_{r} y\right)+\phi\left(J_{r} y, y\right) \leq \phi(x, y)
$$

for all $x \in T^{-1} 0$ and $y \in E$.

An operator $A$ of $C$ into $E^{*}$ is said to be hemicontinuous if for all $x, y \in C$, the mapping $f$ of $[0,1]$ into $E^{*}$ defined by $f(t)=A(t x+(1-t) y)$ is continuous with respect to the weak ${ }^{*}$ topology of $E^{*}$. We denote by $N_{C}(v)$ the normal cone for $C$ at a point $v \in C$, that is, $N_{C}(v)=$ $\left\{x^{*} \in E^{*}:\left\langle v-y, x^{*}\right\rangle \geq 0\right.$ for all $\left.y \in C\right\}$.

Theorem 2.8 (see [19]). Let $C$ be a nonempty closed convex subset of a Banach space E, and $A$ a monotone, hemicontinuous operator of $C$ into $E^{*}$. Let $T \subset E \times E^{*}$ be an operator defined as follows:

$$
T v= \begin{cases}A v+N_{C}(v), & v \in C, \\ \emptyset, & v \notin C .\end{cases}
$$

Then $T$ is maximal monotone and $T^{-1} 0=\operatorname{VI}(C, A)$. 
Lemma 2.9 (see [8]). Let $C$ be a nonempty, closed convex subset of a Banach space $E$ and $A$ a monotone, hemicontinuous operator of $C$ into $E^{*}$. Then

$$
V I(C, A)=\{u \in C:\langle u-v, A v\rangle \geq 0 \forall v \in C\}
$$

It is obvious from Lemma 2.9 that the set $\operatorname{VI}(C, A)$ is a closed convex subset of $C$. Further, we know the following lemma [8, Theorem 7.1.8].

Lemma 2.10 (see [8]). Let $C$ be a nonempty, compact, and convex subset of a Banach space $E$, and $A$ a monotone, hemicontinuous operator of $C$ into $E^{*}$. Then the set $V I(C, A)$ is nonempty.

\section{Main Result}

In this section, we first prove the following strong convergence theorem.

Theorem 3.1. Let $E$ be a 2-uniformly convex and smooth Banach space, $T \subset E \times E^{*}$ be a maximal monotone operator and, let $J_{r}=(J+r T)^{-1} J$ for all $r>0$. Let $C$ be a nonempty closed convex subset of E such that $D(T) \subset C \subset J^{-1}\left(\bigcap_{r>0} R(J+r T)\right)$ and let $A$ be an $\alpha$-inverse-strongly-monotone operator of $C$ into $E^{*}$ with $F:=V I(C, A) \cap T^{-1} 0 \neq \emptyset$ and $\|A y\| \leq\|A y-A u\|$ for all $y \in C$ and $u \in F$. Let $\left\{x_{n}\right\}$ be a sequence defined by $x_{1}=x \in C$ and

$$
\begin{gathered}
y_{n}=\Pi_{C} J^{-1}\left(J x_{n}-\lambda_{n} A x_{n}\right), \\
x_{n+1}=\prod_{C} J^{-1}\left(\alpha_{n} J\left(x_{n}\right)+\left(1-\alpha_{n}\right) J\left(J_{r_{n}} y_{n}\right)\right), \quad n=1,2, \ldots,
\end{gathered}
$$

where $\Pi_{C}$ is the generalized projection from $E$ onto $C,\left\{\alpha_{n}\right\} \subset[0,1],\left\{r_{n}\right\} \subset(0, \infty)$, and $\left\{\lambda_{n}\right\} \subset[a, b]$ for some $a, b$ with $0<a<b<c^{2} \alpha / 2$, where $c$ is a constant in (2.3). Then the sequence $\left\{\Pi_{F}\left(x_{n}\right)\right\}$ converges strongly to an element of $F$, which is a unique element $v \in F$ such that

$$
\lim _{n \rightarrow \infty} \phi\left(v, x_{n}\right)=\min _{y \in F} \lim _{n \rightarrow \infty} \phi\left(y, x_{n}\right),
$$

where $\Pi_{F}$ is the generalized projection from $C$ onto $F$.

Proof. Let $z \in F:=V I(C, A) \cap T^{-1} 0$. By Lemmas 2.5 and 2.6, we have

$$
\begin{aligned}
\phi\left(z, y_{n}\right) & =\phi\left(z, \Pi_{C} J^{-1}\left(J x_{n}-\lambda_{n} A x_{n}\right)\right) \leq \phi\left(z, J^{-1}\left(J x_{n}-\lambda_{n} A x_{n}\right)\right) \\
& =V\left(z, J x_{n}-\lambda_{n} A x_{n}\right) \\
& \leq V\left(z,\left(J x_{n}-\lambda_{n} A x_{n}\right)+\lambda_{n} A x_{n}\right)-2\left\langle J^{-1}\left(J x_{n}-\lambda_{n} A x_{n}\right)-z, \lambda_{n} A x_{n}\right\rangle \\
& =V\left(z, J x_{n}\right)-2 \lambda_{n}\left\langle J^{-1}\left(J x_{n}-\lambda_{n} A x_{n}\right)-z, A x_{n}\right\rangle \\
& =\phi\left(z, x_{n}\right)-2 \lambda_{n}\left\langle x_{n}-z, A x_{n}\right\rangle+2\left\langle J^{-1}\left(J x_{n}-\lambda_{n} A x_{n}\right)-x_{n},-\lambda_{n} A x_{n}\right\rangle
\end{aligned}
$$


for all $n \in \mathbb{N}$. Since $A$ is $\alpha$-inverse-strongly-monotone and $z \in V I(C, A)$, it follows that

$$
\begin{aligned}
-2 \lambda_{n}\left\langle x_{n}-z, A x_{n}\right\rangle & =-2 \lambda_{n}\left\langle x_{n}-z, A x_{n}-A z\right\rangle-2 \lambda_{n}\left\langle x_{n}-z, A z\right\rangle \\
& \leq-2 \alpha \lambda_{n}\left\|A x_{n}-A z\right\|^{2}
\end{aligned}
$$

for all $n \in \mathbb{N}$. By Lemma 2.1, we also have

$$
\begin{aligned}
2\left\langle J^{-1}\left(J x_{n}-\lambda_{n} A x_{n}\right)-x_{n},-\lambda_{n} A x_{n}\right\rangle & \leq 2\left\|J^{-1}\left(J x_{n}-\lambda_{n} A x_{n}\right)-J^{-1}\left(J x_{n}\right)\right\|\left\|\lambda_{n} A x_{n}\right\| \\
& \leq \frac{4}{c^{2}}\left\|\left(J x_{n}-\lambda_{n} A x_{n}\right)-\left(J x_{n}\right)\right\|\left\|\lambda_{n} A x_{n}\right\| \\
& =\frac{4}{c^{2}} \lambda_{n}^{2}\left\|A x_{n}\right\|^{2} \leq \frac{4}{c^{2}} \lambda_{n}^{2}\left\|A x_{n}-A z\right\|^{2}
\end{aligned}
$$

for all $n \in \mathbb{N}$. From (3.3), (3.4) and (3.5), we get

$$
\begin{aligned}
\phi\left(z, y_{n}\right) & \leq \phi\left(z, x_{n}\right)+2 \lambda_{n}\left(\frac{2}{c^{2}} \lambda_{n}-\alpha\right)\left\|A x_{n}-A z\right\|^{2} \\
& \leq \phi\left(z, x_{n}\right)+2 a\left(\frac{2}{c^{2}} b-\alpha\right)\left\|A x_{n}-A z\right\|^{2} \leq \phi\left(z, x_{n}\right)
\end{aligned}
$$

for all $n \in \mathbb{N}$. By Lemmas 2.5 and 2.7 and (3.6), we have

$$
\begin{aligned}
\phi\left(z, x_{n+1}\right) & =\phi\left(z, \Pi_{C} J^{-1}\left(\alpha_{n} J\left(x_{n}\right)+\left(1-\alpha_{n}\right) J\left(J_{r_{n}} y_{n}\right)\right)\right) \\
& \leq \phi\left(z, J^{-1}\left(\alpha_{n} J\left(x_{n}\right)+\left(1-\alpha_{n}\right) J\left(J_{r_{n}} y_{n}\right)\right)\right) \\
& =V\left(z, \alpha_{n} J\left(x_{n}\right)+\left(1-\alpha_{n}\right) J\left(J_{r_{n}} y_{n}\right)\right) \\
& \leq \alpha_{n} V\left(z, J x_{n}\right)+\left(1-\alpha_{n}\right) V\left(z, J\left(J_{r_{n}} y_{n}\right)\right) \\
& =\alpha_{n} \phi\left(z, x_{n}\right)+\left(1-\alpha_{n}\right) \phi\left(z, J_{r_{n}} y_{n}\right) \\
& \leq \alpha_{n} \phi\left(z, x_{n}\right)+\left(1-\alpha_{n}\right)\left(\phi\left(z, y_{n}\right)-\phi\left(J_{r_{n}} y_{n}, y_{n}\right)\right) \\
& \leq \alpha_{n} \phi\left(z, x_{n}\right)+\left(1-\alpha_{n}\right) \phi\left(z, y_{n}\right) \\
& \leq \alpha_{n} \phi\left(z, x_{n}\right)+\left(1-\alpha_{n}\right) \phi\left(z, x_{n}\right)=\phi\left(z, x_{n}\right)
\end{aligned}
$$

for all $n \in \mathbb{N}$. Thus $\lim _{n \rightarrow \infty} \phi\left(z, x_{n}\right)$ exists and hence, $\left\{\phi\left(z, x_{n}\right)\right\}$ is bounded. It implies that $\left\{x_{n}\right\}$ and $\left\{y_{n}\right\}$ are bounded. Define a function $g: F \rightarrow[0, \infty)$ as follows:

$$
g(z)=\lim _{n \rightarrow \infty} \phi\left(z, x_{n}\right), \quad \forall z \in F .
$$


Then, by the same argument as in proof of [4, Theorem 3.1], we obtain $g$ is a continuous convex function and if $\left\|z_{n}\right\| \rightarrow \infty$ then $g\left(z_{n}\right) \rightarrow \infty$. Hence, by [8, Theorem 1.3.11], there exists a point $v \in F$ such that

$$
g(v)=\min _{y \in F} g(y)(:=l)
$$

Put $u_{n}=\Pi_{F} x_{n}$ for all $n \in \mathbb{N}$. We next proof that $u_{n} \rightarrow v$ as $n \rightarrow \infty$. If not, then there exists $\varepsilon_{0}>0$ such that for each $m \in \mathbb{N}$, there is $m^{\prime} \geq m$ satisfying $\left\|u_{m^{\prime}}-v\right\| \geq \varepsilon_{0}$. Since $v \in F$, we have

$$
\phi\left(u_{n}, x_{n}\right)=\phi\left(\Pi_{F} x_{n}, x_{n}\right) \leq \phi\left(v, x_{n}\right)
$$

for all $n \in \mathbb{N}$. This implies that

$$
\lim _{n \rightarrow \infty} \sup \phi\left(u_{n}, x_{n}\right) \leq \lim _{n \rightarrow \infty} \phi\left(v, x_{n}\right)=l
$$

Since $\left(\|v\|-\left\|u_{n}\right\|\right)^{2} \leq \phi\left(v, u_{n}\right) \leq \phi\left(v, x_{n}\right)$ for all $n \in \mathbb{N}$ and $\left\{x_{n}\right\}$ is bounded, the sequence $\left\{u_{n}\right\}$ is also bounded. Applying Lemma 2.2, there exists a strictly increasing, continuous, and convex function $K:[0, \infty) \rightarrow[0, \infty)$ such that $K(0)=0$ and

$$
\left\|\frac{u_{n}+v}{2}\right\|^{2} \leq \frac{1}{2}\left\|u_{n}\right\|^{2}+\frac{1}{2}\|v\|^{2}-\frac{1}{4} K\left(\left\|u_{n}-v\right\|\right)
$$

for all $n \in \mathbb{N}$. Now, choose $b$ satisfying $0<b<(1 / 4) K\left(\varepsilon_{0}\right)$. Hence, there exists $n_{0} \in \mathbb{N}$ such that

$$
\phi\left(u_{n}, x_{n}\right) \leq l+b, \quad \phi\left(v, x_{n}\right) \leq l+b
$$

for all $n \geq n_{0}$. Thus there exists $k \geq n_{0}$ satisfying the following:

$$
\phi\left(u_{k}, x_{k}\right) \leq l+b, \quad \phi\left(v, x_{k}\right) \leq l+b, \quad\left\|u_{k}-v\right\| \geq \varepsilon_{0} .
$$

From (3.7), (3.12), and (3.14), we have

$$
\begin{aligned}
\phi\left(\frac{u_{k}+v}{2}, x_{n+k}\right) & \leq \phi\left(\frac{u_{k}+v}{2}, x_{k}\right) \\
& =\left\|\frac{u_{k}+v}{2}\right\|^{2}-2\left\langle\frac{u_{k}+v}{2}, J x_{k}\right\rangle+\left\|x_{k}\right\|^{2} \\
& \leq \frac{1}{2}\left\|u_{k}\right\|^{2}+\frac{1}{2}\|v\|^{2}-\frac{1}{4} K\left(\left\|u_{k}-v\right\|\right)-\left\langle u_{k}+v, J x_{k}\right\rangle+\left\|x_{k}\right\|^{2} \\
& =\frac{1}{2} \phi\left(u_{k}, x_{k}\right)+\frac{1}{2} \phi\left(v, x_{k}\right)-\frac{1}{4} K\left(\left\|u_{k}-v\right\|\right) \\
& \leq l+b-\frac{1}{4} K\left(\varepsilon_{0}\right)
\end{aligned}
$$


for all $n \in \mathbb{N}$. Hence

$$
l \leq \lim _{n \rightarrow \infty} \phi\left(\frac{u_{k}+v}{2}, x_{n}\right)=\lim _{n \rightarrow \infty} \phi\left(\frac{u_{k}+v}{2}, x_{n+k}\right) \leq l+b-\frac{1}{4} K\left(\varepsilon_{0}\right)<l+b-b=l .
$$

This is a contradiction. Therefore the sequence $\left\{u_{n}\right\}$ converges strongly to $v \in F:=V I(C, A) \cap$ $T^{-1} 0$. Consequently, $v \in F$ is the unique element of $F$ such that

$$
\lim _{n \rightarrow \infty} \phi\left(v, x_{n}\right)=\min _{y \in F} \lim _{n \rightarrow \infty} \phi\left(y, x_{n}\right) .
$$

This completes the proof.

When $C=E$ and $A \equiv 0$ in Theorem 3.1, we obtain the following corollary.

Corollary 3.2 (see Kamimura et al. [4]). Let $E$ be a smooth and uniformly convex Banach space. Let $T \subset E \times E^{*}$ be a maximal monotone operator with $T^{-1} 0 \neq \emptyset$, let $J_{r}=(J+r T)^{-1} J$ for all $r>0$ and let $\Pi_{T^{-1} 0}$ be the generalized projection of $E$ onto $T^{-1} 0$. Let $\left\{x_{n}\right\}$ be a sequence defined by $x_{1}=x \in E$ and

$$
x_{n+1}=J^{-1}\left(\alpha_{n} J\left(x_{n}\right)+\left(1-\alpha_{n}\right) J\left(J_{r_{n}} x_{n}\right)\right),
$$

for every $n=1,2, \ldots$, where $\left\{\alpha_{n}\right\} \subset[0,1],\left\{r_{n}\right\} \subset(0, \infty)$. Then the sequence $\left\{\Pi_{T^{-1} 0}\left(x_{n}\right)\right\}$ converges strongly to an element of $T^{-1} 0$, which is a unique element $v \in T^{-1} 0$ such that

$$
\lim _{n \rightarrow \infty} \phi\left(v, x_{n}\right)=\min _{y \in T^{-1} 0} \lim _{n \rightarrow \infty} \phi\left(y, x_{n}\right) .
$$

Now, we can prove the following weak convergence theorem for finding a common element of the set of zero of a maximal monotone operator and the set of solution of the variational inequality problem for an inverse-strongly-monotone operator in a 2-uniformly convex and uniformly smooth Banach space.

Theorem 3.3. Let E be a 2-uniformly convex and smooth Banach space whose duality mapping $J$ is weakly sequentially continuous. Let $T \subset E \times E^{*}$ be a maximal monotone operator and let $J_{r}=$ $(J+r T)^{-1} J$ for all $r>0$. Let $C$ be a nonempty closed convex subset of $E$ such that $D(T) \subset C \subset$ $J^{-1}\left(\bigcap_{r>0} R(J+r T)\right)$ and let $A$ be an $\alpha$-inverse-strongly-monotone operator of $C$ into $E^{*}$ with $F:=$ $\operatorname{VI}(C, A) \cap T^{-1} 0 \neq \emptyset$ and $\|A y\| \leq\|A y-A u\|$ for all $y \in C$ and $u \in F$. Let $\left\{\alpha_{n}\right\} \subset[0,1],\left\{r_{n}\right\} \subset(0, \infty)$ such that $\limsup _{n \rightarrow \infty} \alpha_{n}<1$ and $\liminf _{n \rightarrow \infty} r_{n}>0$, and let $\left\{\lambda_{n}\right\} \subset[a, b]$ for some $a, b$ with $0<a<b<c^{2} \alpha / 2$, where $c$ is a constant in (2.3). Let $\left\{x_{n}\right\}$ be a sequence generated by (3.1). Then the sequence $\left\{x_{n}\right\}$ converges weakly to an element $v$ of $F$. Further $v=\lim _{n \rightarrow \infty} \Pi_{F}\left(x_{n}\right)$.

Proof. As in proof of Theorem 3.1, we have $\left\{x_{n}\right\}$ and $\left\{y_{n}\right\}$ are bounded. It holds from (3.7) and (3.6) that

$$
\left(1-\alpha_{n}\right) \phi\left(J_{r_{n}} y_{n}, y_{n}\right) \leq \phi\left(z, x_{n}\right)-\phi\left(z, x_{n+1}\right)
$$


for all $n \in \mathbb{N}$. Since $\limsup _{n \rightarrow \infty} \alpha_{n}<1$, it follows that $\lim _{n \rightarrow \infty} \phi\left(J_{r_{n}} y_{n}, y_{n}\right)=0$. Applying Lemma 2.3, we have $\lim _{n \rightarrow \infty}\left\|J_{r_{n}} y_{n}-y_{n}\right\|=0$. Since $E$ is uniformly smooth, the duality mapping $J$ is uniformly norm-to-norm continuous on each bounded subset of $E$. Thus

$$
\lim _{n \rightarrow \infty}\left\|J\left(J_{r_{n}} y_{n}\right)-J\left(y_{n}\right)\right\|=0
$$

By (3.7) and (3.6), we note that

$$
-2 a\left(\frac{2}{c^{2}} b-\alpha\right)\left(1-\alpha_{n}\right)\left\|A x_{n}-A z\right\|^{2} \leq \phi\left(z, x_{n}\right)-\phi\left(z, x_{n+1}\right)
$$

for all $n \in \mathbb{N}$ and hence $\lim _{n \rightarrow \infty}\left\|A x_{n}-A z\right\|^{2}=0$. From Lemmas 2.5 and 2.6 and (3.5), we have

$$
\begin{aligned}
\phi\left(x_{n}, y_{n}\right) & =\phi\left(x_{n}, \Pi_{C} J^{-1}\left(J x_{n}-\lambda_{n} A x_{n}\right)\right) \leq \phi\left(x_{n}, J^{-1}\left(J x_{n}-\lambda_{n} A x_{n}\right)\right) \\
& =V\left(x_{n}, J x_{n}-\lambda_{n} A x_{n}\right) \\
& \leq V\left(x_{n},\left(J x_{n}-\lambda_{n} A x_{n}\right)+\lambda_{n} A x_{n}\right)-2\left\langle J^{-1}\left(J x_{n}-\lambda_{n} A x_{n}\right)-x_{n}, \lambda_{n} A x_{n}\right\rangle \\
& =\phi\left(x_{n}, x_{n}\right)+2\left\langle J^{-1}\left(J x_{n}-\lambda_{n} A x_{n}\right)-x_{n},-\lambda_{n} A x_{n}\right\rangle \\
& =\frac{4}{c^{2}} \lambda_{n}^{2}\left\|A x_{n}-A z\right\|^{2} \leq \frac{4}{c^{2}} b^{2}\left\|A x_{n}-A z\right\|^{2}
\end{aligned}
$$

for all $n \in \mathbb{N}$. Since $\lim _{n \rightarrow \infty}\left\|A x_{n}-A z\right\|^{2}=0$, we have $\lim _{n \rightarrow \infty} \phi\left(x_{n}, y_{n}\right)=0$. Applying Lemma 2.3, we obtain $\lim _{n \rightarrow \infty}\left\|x_{n}-y_{n}\right\|=0$. From the uniform smoothness of $E$, we have $\lim _{n \rightarrow \infty}\left\|J x_{n}-J y_{n}\right\|=0$. Since $\left\{x_{n}\right\}$ is bounded, there exists a subsequence $\left\{x_{n_{i}}\right\}$ of $\left\{x_{n}\right\}$ such that $x_{n_{i}} \rightarrow u \in E$. It follows that $y_{n_{i}} \rightarrow u$ as $i \rightarrow \infty$. We will show that $u \in F$. Since $\lim _{n \rightarrow \infty} r_{n}>0$, it follows from (3.21) that

$$
\lim _{n \rightarrow \infty}\left\|A_{r_{n}} y_{n}\right\|=\lim _{n \rightarrow \infty} \frac{1}{r_{n}}\left\|J y_{n}-J\left(J_{r_{n}} y_{n}\right)\right\|=0
$$

If $\left(z, z^{*}\right) \in T$, then it holds from the monotonicity of $T$ that

$$
\left\langle z-y_{n_{i}}, z^{*}-A_{r_{i}} y_{n_{i}}\right\rangle \geq 0
$$

for all $i \in \mathbb{N}$. Letting $i \rightarrow \infty$, we get $\left\langle z-u, z^{*}\right\rangle \geq 0$. Then, the maximality of $T$ implies $u \in T^{-1} 0$. Next, we show that $u \in V I(C, A)$. Let $B \subset E \times E^{*}$ be an operator as follows:

$$
B v:= \begin{cases}A v+N_{C}(v), & v \in C, \\ \emptyset, & v \notin C .\end{cases}
$$


By Theorem 2.8, $B$ is maximal monotone and $B^{-1} 0=V I(C, A)$. Let $(v, w) \in G(B)$. Since $w \in B v=A v+N_{C}(v)$, it follows that $w-A v \in N_{C}(v)$. From $y_{n} \in C$, we have

$$
\left\langle v-y_{n}, w-A v\right\rangle \geq 0
$$

On the other hand, from $y_{n}=\Pi_{C} J^{-1}\left(J x_{n}-\lambda_{n} A x_{n}\right)$ and Lemma 2.4, we have $\left\langle v-y_{n}, J y_{n}-\right.$ $\left.\left(J x_{n}-\lambda_{n} A x_{n}\right)\right\rangle \geq 0$ and hence

$$
\left\langle v-y_{n}, \frac{J x_{n}-J y_{n}}{\lambda_{n}}-A x_{n}\right\rangle \leq 0
$$

Then it follows from (3.27) and (3.28) that

$$
\begin{aligned}
\left\langle v-y_{n}, w\right\rangle & \geq\left\langle v-y_{n}, A v\right\rangle \\
& \geq\left\langle v-y_{n}, A v\right\rangle+\left\langle v-y_{n}, \frac{J x_{n}-J y_{n}}{\lambda_{n}}-A x_{n}\right\rangle \\
& =\left\langle v-y_{n}, A v-A x_{n}\right\rangle+\left\langle v-y_{n}, \frac{J x_{n}-J y_{n}}{\lambda_{n}}\right\rangle \\
& =\left\langle v-y_{n}, A v-A y_{n}\right\rangle+\left\langle v-y_{n}, A y_{n}-A x_{n}\right\rangle+\left\langle v-y_{n}, \frac{J x_{n}-J y_{n}}{\lambda_{n}}\right\rangle \\
& \geq-\left\|v-y_{n}\right\| \frac{\left\|y_{n}-x_{n}\right\|}{\alpha}-\left\|v-y_{n}\right\| \frac{\left\|J x_{n}-J y_{n}\right\|}{a} \\
& \geq-M\left(\frac{\left\|y_{n}-x_{n}\right\|}{\alpha}+\frac{\left\|J x_{n}-J y_{n}\right\|}{a}\right)
\end{aligned}
$$

for all $n \in \mathbb{N}$, where $M=\sup \left\{\left\|v-y_{n}\right\|: n \in \mathbb{N}\right\}$. Taking $n=n_{i}$, we have $\langle v-u, w\rangle \geq 0$ as $i \rightarrow \infty$. Hence, by the maximality of $B$, we obtain $u \in B^{-1} 0=V I(C, A)$ and therefore $u \in F$. By Theorem 3.1, the $\left\{\Pi_{F}\left(x_{n}\right)\right\}$ converges strongly to a point $v \in F$ which is a unique element of $F$ such that

$$
\lim _{n \rightarrow \infty} \phi\left(v, x_{n}\right)=\min _{y \in F} \lim _{n \rightarrow \infty} \phi\left(y, x_{n}\right) .
$$

By the uniform smoothness of $E$, we also have $\lim _{n \rightarrow \infty}\left\|J \Pi_{F} x_{n_{i}}-J v\right\|=0$. Finally we prove that $u=v$. From Lemma 2.4 and $u \in F$, we have

$$
\left\langle u-\Pi_{F} x_{n_{i}}, J x_{n_{i}}-J \Pi_{F} x_{n_{i}}\right\rangle \leq 0
$$

for all $i \in \mathbb{N}$. Since $J$ is weakly sequentially continuous, we have $J x_{n_{i}} \rightarrow J u$ as $i \rightarrow \infty$. Letting $i \rightarrow \infty$ in (3.31), we get

$$
\langle u-v, J u-J v\rangle \leq 0 .
$$


This implies $\langle u-v, J u-J v\rangle=0$. Since $E$ is strictly convex, it follows that $u=v$. Therefore the sequence $\left\{x_{n}\right\}$ converges weakly to $v=\lim _{n \rightarrow \infty} \Pi_{F}\left(x_{n}\right)$. This completes the proof.

When $C=E$ and $A \equiv 0$ in Theorem 3.3, we obtain the following result.

Corollary 3.4 (see Kamimura et al. [4]). Let E be a uniformly convex and uniformly smooth Banach space whose duality mapping $J$ is weakly sequentially continuous. Let $T \subset E \times E^{*}$ be a maximal monotone operator with $T^{-1} 0 \neq \emptyset$, let $J_{r}=(J+r T)^{-1} J$ for all $r>0$ and let $\left\{x_{n}\right\}$ be a sequence defined by $x_{1}=x \in E$ and

$$
x_{n+1}=J^{-1}\left(\alpha_{n} J\left(x_{n}\right)+\left(1-\alpha_{n}\right) J\left(J_{r_{n}} x_{n}\right)\right),
$$

for every $n=1,2, \ldots$, where $\left\{\alpha_{n}\right\} \subset[0,1],\left\{r_{n}\right\} \subset(0, \infty)$ satisfy $\limsup _{n \rightarrow \infty} \alpha_{n}<1$ and $\liminf _{n \rightarrow \infty} r_{n}>0$. Then the sequence $\left\{x_{n}\right\}$ converges weakly to an element $v$ of $T^{-1} 0$. Further $v=\lim _{n \rightarrow \infty} \Pi_{T^{-1} 0}\left(x_{n}\right)$.

When $\alpha_{n}=0$ and $T \equiv 0$ in Theorem 3.3, we have the following corollary.

Corollary 3.5 (see Iiduka and Takahashi [6]). Let E be a 2-uniformly convex and uniformly smooth Banach space whose duality mapping $J$ is weakly sequentially continuous. Let $C$ be a nonempty closed convex subset of $E$ and let $A$ be an $\alpha$-inverse-strongly-monotone operator of $C$ into $E^{*}$ with $V I(C, A) \neq \emptyset$. Assume that $\|A y\| \leq\|A y-A u\|$ for all $y \in C$ and $u \in V I(C, A)$. Let $\left\{\lambda_{n}\right\} \subset[a, b]$ for some $a, b$ with $0<a<b<c^{2} \alpha / 2$, where $c$ is a constant in (2.3). Let $\left\{x_{n}\right\}$ be a sequence defined by $x_{1}=x \in C$ and

$$
x_{n+1}=\Pi_{C} J^{-1}\left(J x_{n}-\lambda_{n} A x_{n}\right),
$$

for every $n=1,2, \ldots$, where $\Pi_{C}$ is the generalized projection from $E$ onto $C$. Then the sequence $\left\{x_{n}\right\}$ converges weakly to an element $v$ in $\operatorname{VI}(C, A)$. Further $v=\lim _{n \rightarrow \infty} \Pi_{V I(C, A)}\left(x_{n}\right)$.

\section{Application}

In this section, we prove some weak convergence theorems in a 2-uniformly convex, uniformly smooth Banach space by using Theorem 3.3. We first apply Theorem 3.3 to the convex minimization problem.

Theorem 4.1. Let E be a 2-uniformly convex and uniformly smooth Banach space whose duality mapping $J$ is weakly sequentially continuous and let $f: E \rightarrow(-\infty, \infty]$ be a proper lower semicontinuous convex function. Let $C$ be a nonempty closed convex subset of $E$ such that $D(\partial f) \subset$ $C \subset J^{-1}\left(\bigcap_{r>0} R(J+r \partial f)\right)$ and let $A$ be an $\alpha$-inverse-strongly-monotone operator of $C$ into $E^{*}$ with $F:=V I(C, A) \cap(\partial f)^{-1} 0 \neq \emptyset$ and $\|A y\| \leq\|A y-A u\|$ for all $y \in C$ and $u \in F$. Let $\left\{x_{n}\right\}$ be a sequence defined as follows: $x_{1}=x \in C$ and

$$
\begin{gathered}
z_{n}=\Pi_{C} J^{-1}\left(J x_{n}-\lambda_{n} A x_{n}\right), \\
y_{n}=\arg \min _{y \in C}\left\{f(y)+\frac{1}{2 r_{n}}\|y\|^{2}-\frac{1}{r_{n}}\left\langle y, J z_{n}\right\rangle\right\}, \\
x_{n+1}=\Pi_{C} J^{-1}\left(\alpha_{n} J\left(x_{n}\right)+\left(1-\alpha_{n}\right) J\left(y_{n}\right)\right),
\end{gathered}
$$


for every $n=1,2, \ldots$, where $\Pi_{C}$ is the generalized projection from $E$ onto $C,\left\{\alpha_{n}\right\} \subset[0,1],\left\{r_{n}\right\} \subset$ $(0, \infty)$ satisfy $\limsup _{n \rightarrow \infty} \alpha_{n}<1$ and $\liminf _{n \rightarrow \infty} r_{n}>0$, and $\left\{\lambda_{n}\right\} \subset[a, b]$ for some $a, b$ with $0<a<b<c^{2} \alpha / 2$, where $c$ is a constant in (2.3). Then the sequence $\left\{x_{n}\right\}$ converges weakly to an element $v$ of $F:=\operatorname{VI}(C, A) \cap(\partial f)^{-1} 0$. Further $v=\lim _{n \rightarrow \infty} \Pi_{F}\left(x_{n}\right)$.

Proof. By Rockafellar's theorem [20, 21], the subdifferential mapping $\partial f \subset E \times E^{*}$ is maximal monotone. Let $J_{r}=(J+r \partial f)^{-1} J$ for all $r>0$. As in the proof of [4, Theorem 4.1], we have $y_{n}=$ $J_{r_{n}} z_{n}$ for all $n \in \mathbb{N}$. Hence, by Theorem 3.3, $\left\{x_{n}\right\}$ converges weakly to $v=\lim _{n \rightarrow \infty} \Pi_{F}\left(x_{n}\right)$.

Next, we study the problem of finding a zero point of a maximal monotone operator of $E$ into $E^{*}$ and a minimizer of a continuously Fréchet differentiable, convex functional in a Banach space. To prove this, we need the following lemma.

Lemma 4.2 (see [22]). Let $E$ be a Banach space, $f$ a continuously Fréchet differentiable, convex function on $E$, and $\nabla f$ the gradient of $f$. If $\nabla f$ is $1 / \alpha$-Lipschitz continuous, then $\nabla f$ is $\alpha$-inversestrongly-monotone.

Theorem 4.3. Let E be a 2-uniformly convex and uniformly smooth Banach space whose duality mapping $J$ is weakly sequentially continuous. Let $T \subset E \times E^{*}$ be a maximal monotone operator and let $J_{r}=(J+r T)^{-1} J$ for all $r>0$. Let $C$ be a nonempty closed convex subset of $E$ such that $D(T) \subset C \subset$ $J^{-1}\left(\bigcap_{r>0} R(J+r T)\right)$. Assume that $f$ is a function on $E$ satisfies the following:

(1) $f$ is a continuously Fréchet differentiable convex function on $E$, and $\nabla f$ is $1 / \alpha$-Lipschitz continuous;

(2) $S=\arg \min _{y \in C} f(y)=\left\{z \in C: f(z)=\min _{y \in C} f(y)\right\} \cap T^{-1} 0 \neq \emptyset$;

(3) $\left\|\left.\nabla f\right|_{C}(y)\right\| \leq\left\|\left.\nabla f\right|_{C}(y)-\left.\nabla f\right|_{C}(u)\right\|$ for all $y \in C$ and $u \in S \cap T^{-1} 0$.

Suppose that $x_{1}=x \in C$ and $\left\{x_{n}\right\}$ is given by

$$
\begin{gathered}
y_{n}=\Pi_{C} J^{-1}\left(J x_{n}-\left.\lambda_{n} \nabla f\right|_{C}\left(x_{n}\right)\right), \\
x_{n+1}=\Pi_{C} J^{-1}\left(\alpha_{n} J\left(x_{n}\right)+\left(1-\alpha_{n}\right) J\left(J_{r_{n}} y_{n}\right)\right),
\end{gathered}
$$

for every $n=1,2, \ldots$, where $\Pi_{C}$ is the generalized projection from $E$ onto $C$ and $\left\{\alpha_{n}\right\} \subset[0,1]$, $\left\{r_{n}\right\} \subset(0, \infty)$ satisfy limsup $\sup _{n \rightarrow \infty} \alpha_{n}<1$ and $\liminf _{n \rightarrow \infty} r_{n}>0$ and $\left\{\lambda_{n}\right\} \subset[a, b]$ for some $a, b$ with $0<a<b<c^{2} \alpha / 2$, where $c$ is a constant in (2.3). Then the sequence $\left\{x_{n}\right\}$ converges weakly to some element $v$ in $F:=T^{-1} 0 \cap S$. Further $v=\lim _{n \rightarrow \infty} \Pi_{F}\left(x_{n}\right)$.

Proof. It follows from Lemma 4.2 and the condition (1) that $\left.\nabla f\right|_{C}$ is an $\alpha$-inversestrongly-monotone operator of $C$ into $E^{*}$. We also obtain from the convexity and Fréchet differentiability of $f$ that

$$
V I\left(C,\left.\nabla f\right|_{C}\right)=\arg \min _{y \in C} f(y)
$$

By using Theorem 3.3, $\left\{x_{n}\right\}$ converges weakly to some element $v$ in $F:=T^{-1} 0 \cap S$.

We next consider the problem of finding a zero point of a maximal monotone operator of $E$ into $E^{*}$ and a zero point of an inverse-strongly-monotone operator of $E$ into $E^{*}$. In the case where $C=E$. 
Theorem 4.4. Let E be a 2-uniformly convex and uniformly smooth Banach space whose duality mapping $J$ is weakly sequentially continuous. Let $T \subset E \times E^{*}$ be a maximal monotone operator and let $J_{r}=(J+r T)^{-1} J$ for all $r>0$. Let $A$ be an $\alpha$-inverse-strongly-monotone of $E$ into $E^{*}$ with $A^{-1} 0 \cap$ $T^{-1} 0 \neq \emptyset$. Let $x_{1}=x \in E$ and $\left\{x_{n}\right\}$ is given by

$$
\begin{gathered}
y_{n}=J^{-1}\left(J x_{n}-\lambda_{n} A x_{n}\right), \\
x_{n+1}=J^{-1}\left(\alpha_{n} J\left(x_{n}\right)+\left(1-\alpha_{n}\right) J\left(J_{r_{n}} y_{n}\right)\right),
\end{gathered}
$$

for every $n=1,2, \ldots$, where $\left\{\alpha_{n}\right\} \subset[0,1],\left\{r_{n}\right\} \subset(0, \infty)$ satisfy $\limsup _{n \rightarrow \infty} \alpha_{n}<1$ and $\liminf _{n \rightarrow \infty} r_{n}>0$ and $\left\{\lambda_{n}\right\} \subset[a, b]$ for some $a, b$ with $0<a<b<c^{2} \alpha / 2$, where $c$ is a constant in (2.3). Then the sequence $\left\{x_{n}\right\}$ converges weakly to some element $v$ in $F:=T^{-1} 0 \cap A^{-1} 0$. Further $v=\lim _{n \rightarrow \infty} \Pi_{F}\left(x_{n}\right)$.

Proof. From $\Pi_{E}=I, V I(E, A)=A^{-1} 0$, and $\|A y\|=\|A y-0\|=\|A y-A u\|$ for all $y \in E$ and $u \in$ $A^{-1} 0$, by using Theorem 3.3, $\left\{x_{n}\right\}$ converges weakly to some element $v$ in $F:=T^{-1} 0 \cap A^{-1} 0$.

Corollary 4.5. Let E be a 2-uniformly convex and uniformly smooth Banach space whose duality mapping $J$ is weakly sequentially continuous. Let $T \subset E \times E^{*}$ be a maximal monotone operator and let $J_{r}=(J+r T)^{-1} J$ for all $r>0$. Assume that $f$ is a function on $E$ such that $f$ is a continuously Fréchet differentiable convex function on $E, \nabla f$ is $1 / \alpha$-Lipschitz continuous, and $(\nabla f)^{-1} 0=\{z \in E: f(z)=$ $\left.\min _{y \in E} f(y)\right\} \cap T^{-1} 0 \neq \emptyset$. Let $\left\{x_{n}\right\}$ be a sequence generated by $x_{1}=x \in E$ and

$$
\begin{gathered}
y_{n}=J^{-1}\left(J x_{n}-\lambda_{n} \nabla f x_{n}\right), \\
x_{n+1}=J^{-1}\left(\alpha_{n} J\left(x_{n}\right)+\left(1-\alpha_{n}\right) J\left(J_{r_{n}} y_{n}\right)\right),
\end{gathered}
$$

for every $n=1,2, \ldots$, where $\left\{\alpha_{n}\right\} \subset[0,1],\left\{r_{n}\right\} \subset(0, \infty)$ satisfy $\limsup _{n \rightarrow \infty} \alpha_{n}<1$ and $\liminf _{n \rightarrow \infty} r_{n}>0$ and $\left\{\lambda_{n}\right\} \subset[a, b]$ for some $a, b$ with $0<a<b<c^{2} \alpha / 2$, where $c$ is a constant in (2.3). Then the sequence $\left\{x_{n}\right\}$ converges weakly to some element $v$ in $F:=T^{-1} 0 \cap(\nabla f)^{-1} 0$. Further $v=\lim _{n \rightarrow \infty} \Pi_{F}\left(x_{n}\right)$.

Proof. By Lemma 4.2, we have $\nabla f$ is an $\alpha$-inverse-strongly-monotone operator of $E$ into $E^{*}$. Hence, by Theorem 4.4, $\left\{x_{n}\right\}$ converges weakly to some element $v$ in $F:=T^{-1} 0 \cap(\nabla f)^{-1} 0$.

Finally we consider the complementary problem. Let $K$ be a nonempty closed convex cone in $E, A$ an operator of $K$ into $E^{*}$. We define its polar in $E^{*}$ to be the set

$$
K^{*}=\left\{y^{*} \in E^{*}:\left\langle x, y^{*}\right\rangle \geq 0 \forall x \in K\right\}
$$

Then an element $u \in K$ is called a solution of the complementarity problem if

$$
A u \in K^{*}, \quad\langle u, A u\rangle=0 .
$$

The set of solutions of the complementarity problem is denoted by $C(K, A)$. 
Theorem 4.6. Let E be a 2-uniformly convex and uniformly smooth Banach space whose duality mapping $J$ is weakly sequentially continuous. Let $T \subset E \times E^{*}$ be a maximal monotone operator and let $J_{r}=(J+r T)^{-1} J$ for all $r>0$. Let $K$ be a nonempty closed convex cone of $E$ such that $D(T) \subset K \subset$ $J^{-1}\left(\bigcap_{r>0} R(J+r T)\right)$. Let $A$ be an $\alpha$-inverse-strongly-monotone of $K$ into $E^{*}$ with $F:=C(K, A) \cap$ $T^{-1} 0 \neq \emptyset$ and $\|A y\| \leq\|A y-A u\|$ for all $y \in K$ and $u \in F$. Suppose that $x_{1}=x \in K$ and $\left\{x_{n}\right\}$ is given by

$$
\begin{gathered}
y_{n}=\Pi_{K} J^{-1}\left(J x_{n}-\lambda_{n} A x_{n}\right), \\
x_{n+1}=\Pi_{K} J^{-1}\left(\alpha_{n} J\left(x_{n}\right)+\left(1-\alpha_{n}\right) J\left(J_{r_{n}} y_{n}\right)\right),
\end{gathered}
$$

for every $n=1,2, \ldots$, where $\Pi_{K}$ is the generalized projection from $E$ onto $K$ and $\left\{\alpha_{n}\right\} \subset[0,1]$, $\left\{r_{n}\right\} \subset(0, \infty)$ satisfy limsup $\sup _{n \rightarrow \infty} \alpha_{n}<1$ and $\liminf _{n \rightarrow \infty} r_{n}>0$ and $\left\{\lambda_{n}\right\} \subset[a, b]$ for some $a, b$ with $0<a<b<c^{2} \alpha / 2$, where $c$ is a constant in (2.3). Then the sequence $\left\{x_{n}\right\}$ converges weakly to some element $v$ in $F:=T^{-1} 0 \cap C(K, A)$. Further $v=\lim _{n \rightarrow \infty} \Pi_{F}\left(x_{n}\right)$.

Proof. It follows by of $\left[8\right.$, Lemma 7.11] that $\operatorname{VI}(K, A)=C(K, A)$. Hence, Theorem 3.3, $\left\{x_{n}\right\}$ converges weakly to some element $v$ in $F:=T^{-1} 0 \cap C(K, A)$.

\section{Acknowledgment}

The authors thank the Commission on Higher Education for their financial support.

\section{References}

[1] R. T. Rockafellar, "Monotone operators and the proximal point algorithm," SIAM Journal on Control and Optimization, vol. 14, no. 5, pp. 877-898, 1976.

[2] S. Kamimura and W. Takahashi, "Strong convergence of a proximal-type algorithm in a Banach space," SIAM Journal on Optimization, vol. 13, no. 3, pp. 938-945, 2002.

[3] S. Ohsawa and W. Takahashi, "Strong convergence theorems for resolvents of maximal monotone operators in Banach spaces," Archiv der Mathematik, vol. 81, no. 4, pp. 439-445, 2003.

[4] S. Kamimura, F. Kohsaka, and W. Takahashi, "Weak and strong convergence theorems for maximal monotone operators in a Banach space," Set-Valued Analysis, vol. 12, no. 4, pp. 417-429, 2004.

[5] H. Iiduka, W. Takahashi, and M. Toyoda, "Approximation of solutions of variational inequalities for monotone mappings," PanAmerican Mathematical Journal, vol. 14, no. 2, pp. 49-61, 2004.

[6] H. Iiduka and W. Takahashi, "Weak convergence of a projection algorithm for variational inequalities in a Banach space," Journal of Mathematical Analysis and Applications, vol. 339, no. 1, pp. 668-679, 2008.

[7] G. M. Korpelevich, "An extragradient method for finding saddle points and for other problems," Matecon, vol. 12, no. 4, pp. 747-756, 1976.

[8] W. Takahashi, Nonlinear Functional Analysis, Fixed Point Theory and Its Application, Yokohama Publishers, Yokohama, Japan, 2000.

[9] J. Diestel, Geometry of Banach Spaces-Selected Topics, vol. 485 of Lecture Notes in Mathematics, Springer, Berlin, Germany, 1975.

[10] K. Ball, E. A. Carlen, and E. H. Lieb, "Shap uniform convexity and smoothness inequalities for trace norms," Inventiones Mathematicae, vol. 26, no. 3, pp. 137-150, 1977.

[11] Y. Takahashi, K. Hashimoto, and M. Kato, “On sharp uniform convexity, smoothness, and strong type, cotype inequalities," Journal of Nonlinear and Convex Analysis, vol. 3, no. 2, pp. 267-281, 2002.

[12] B. Beauzamy, Introduction to Banach Spaces, and Their Geometry, Noth-Holland, Amsterdam, The Netherlands, 2nd edition, 1995.

[13] H. K. Xu, "Inequalities in Banach spaces with applications," Nonlinear Analysis: Theory, Methods $\mathcal{E}$ Applications, vol. 16, no. 12, pp. 1127-1138, 1991. 
[14] Ya. I. Alber, "Metric and generalized projection operators in Banach spaces: properties and applications," in Theory and Applications of Nonlinear Operators of Accretive and Monotone Type, A. G. Kartsatos, Ed., vol. 178 of Lecture Notes in Pure and Applied Mathematics, pp. 15-50, Marcel Dekker, New York, NY, USA, 1996.

[15] S. Reich, "A weak convergence theorem for the alternating method with Bregman distances," in Theory and Applications of Nonlinear Operators of Accretive and Monotone Type, A. G. Kartsatos, Ed., vol. 178 of Lecture Notes in Pure and Applied Mathematics, pp. 313-318, Marcel Dekker, New York, NY, USA, 1996.

[16] V. Barbu, Nonlinear Semigroups and Differential Equations in Banach Spaces, Editura Academiei Republicii Socialiste România, Bucharest, Romania, 1976.

[17] W. Takahashi, Convex Analysis and Approximation of Fixed Points, vol. 2 of Mathematical Analysis Series, Yokohama Publishers, Yokohama, Japan, 2000.

[18] F. Kohsaka and W. Takahashi, "Strong convergence of an iterative sequence for maximal monotone operators in a Banach space," Abstract and Applied Analysis, vol. 2004, no. 3, pp. 239-249, 2004.

[19] R. T. Rockafellar, "On the maximality of sums of nonlinear monotone operators," Transactions of the American Mathematical Society, vol. 149, pp. 75-88, 1970.

[20] R. T. Rockafellar, "Characterization of the subdifferentials of convex functions," Pacific Journal of Mathematics, vol. 17, pp. 497-510, 1966.

[21] R. T. Rockafellar, “On the maximal monotonicity of subdifferential mappings," Pacific Journal of Mathematics, vol. 33, pp. 209-216, 1970.

[22] J.-B. Baillon and G. Haddad, "Quelques propriétés des opérateurs angle-bornés et $n$-cycliquement monotones," Israel Journal of Mathematics, vol. 26, no. 2, pp. 137-150, 1977. 